\title{
ТЕНДЕНЦИИ И ПЕРСПЕКТИВЫ РАЗВИТИЯ СОВРЕМЕННОГО СТРОИТЕЛЬСТВА В РОССИИ С ТОЧКИ ЗРЕНИЯ ЭКОНОМИКИ
}

\author{
(c) 2020 Мажанская Елизавета Владимировна \\ бакалавр, студент магистратуры кафедры «Экспертиза и управление недвижимостью» \\ Сибирский федеральный университет, Россия, Красноярск \\ E-mail: mazhanskaya97@mail.ru \\ (c) 2020 Пасечник Анастасия Сергеевна \\ студент специалитета кафедры «Строительство уникальных зданий и сооружений» \\ Сибирский федеральный университет, Россия, Красноярск \\ E-mail: pasechnicnastya14@mail.ru \\ (c) 2020 Беккер Мария Станиславовна \\ студент специалитета кафедры «Строительство уникальных зданий и сооружений» \\ Сибирский федеральный университет, Россия, Красноярск \\ E-mail: mary.bekker.98@mail.ru \\ (C) 2020 Полегенько Анастасия Валерьевна \\ студент специалитета кафедры «Строительство уникальных зданий и сооружений» \\ Сибирский федеральный университет, Россия, Красноярск \\ E-mail: apolegenko@inbox.ru \\ (c) 2020 Родионенко Евгения Викторовна \\ студент бакалавра кафедры «Промышленное и гражданское строительство» \\ Сибирский федеральный университет, Россия, Красноярск \\ E-mail: rodionaaaa@mail.ru
}

Строительный рынок в РФ в настоящее время находится на переднем крае ЕАЭС и является одним из самых быстрорастущих на континенте. Более того, все указывает на то, что в ближайшие годы этот сектор будет процветать.

Специалисты отрасли соглашаются - на строительном рынке уже несколько месяцев наблюдается положительная динамика. Увеличивается количество сданных квартир, начаты дополнительные инвестиции за счет средств федеральных программ. Что отличает РФ от других стран, так это гораздо большая доля нового строительства с точки зрения национальных инвестиций, в то время как в других странах ЕАЭС реконструкция существующих зданий занимает гораздо большую долю. Это явление связано с историческими условиями и нынешним бумом строительства.

Ключевые слова: современное строительство, строительный рынок, строительный сектор экономики, инновации в строительстве.

Строительная отрасль играет значительную роль в социально-экономическом развитии любой страны, являясь важным фактором ее стабильности, а также служит материальной основой непрерывного развития народного хозяйства, решения жилищной проблемы, повышения материального и культурного уровня народа [1].

Гражданское строительство как особый вид деятельности является неотъемлемой частью национальной экономики и вносит значительный вклад в конкурентоспособность страны, обеспечивая ее общий экономический рост. В России строительный сектор экономики представляет собой важный промышленный комплекс, занимающий значительное место в структуре ВВП со значением 6,4\% (2017-2018 гг.). Динамика развития гражданского строительства на протяжении почти двух десятилетий не позволяет оценить какие-либо качественные изменения в этой области.

Однако экономический рост в настоящее время невозможен без широкого использования инноваций (как технических, так и организационно-экономических). В частности, 
этот аспект в гражданском строительстве демонстрирует крайне низкое развитие.

По данным Федеральной службы государственной статистики, объем инвестиций в гражданское строительство ежегодно неуклонно увеличивался с 2012 года (таблица 1) (Росстат, 2019A), но причиной их сокращения стал экономический кризис 2014 года. Однако гражданское строительство остается одним из наиболее привлекательных видов экономической деятельности для инвестиций.

Количество введенных в эксплуатацию зданий в Российской Федерации росло до 2016 года, но затем началось снижение

В 2018 году этот показатель составил 272,6 тыс. и он снизился на $11 \%$ по сравнению с 2016 годом (Росстат, 2019А) (таблица 2).

Объем работ по внешнеэкономической деятельности «гражданское строительство», выполненных в 2016 году в России, составил 7545,9 млрд. руб. (Росстат, 2019 г.), что составляет 98,6\% по сравнению с предыдущим годом (таблица 3).

В 2000-2009 годах этот объем ежегодно увеличивался в среднем на 12,4\%. Однако в 2010 году произошло резкое падение: на $13,2 \%$ по сравнению с предыдущим годом. Затем ситу- ация нормализовалась в 2011 году. Начиная с 2014 года, наблюдался спад (на 2,3\%), но объем работ увеличился в 2018 году, и падение составило всего 1,4\% [3, с. 256].

Одним из показателей, позволяющих определить состояние и динамику гражданского строительства, является индекс деловой уверенности. Это среднее арифметическое «остатков» оценок уровня производственной программы и ожидаемых изменений численности занятых. «Баланс»- это разница между процентом положительных и отрицательных ответов.

По данным Росстата, индекс деловой уверенности в гражданском строительстве в 1 квартале 2020 года составил $(-20) \%$, а по сравнению с 4 кварталом 2019 года, когда ИдУ составлял (-25)\% (по данным официального сайта Росстата), он вырос на 5\%. Отрицательное значение свидетельствует о текущей низкой деловой активности в гражданском строительстве. Среди значимых причин респонденты указали нехватку квалифицированных кадров (по данным официального сайта Федеральной службы государственной статистики) [7].

Представления о качественной структуре активов человеческого капитала в российской

Таблица 1. Инвестиции в основной капитал для внешнеэкономической деятельности «гражданское строительство»

\begin{tabular}{|l|c|c|c|c|c|c|c|}
\hline \multicolumn{1}{|c|}{ Год } & 2012 & 2013 & 2014 & 2015 & 2016 & 2017 & 2018 \\
\hline $\begin{array}{l}\text { Инвестиции в } \\
\text { основной капитал }\end{array}$ & 336.8 & 348.6 & 438.1 & 469.3 & 401.2 & 443.8 & 266.5 \\
\hline
\end{tabular}

Таблица 2. Ввод в эксплуатацию жилых и нежилых зданий в Российской Федерации

\begin{tabular}{|c|c|c|c|c|c|c|}
\hline Год & 2013 & 2014 & 2015 & 2016 & 2017 & 2018 \\
\hline $\begin{array}{l}\text { Введенных в эксплуатацию } \\
\text { зданий - всего, тыс. }\end{array}$ & 241.4 & 258.1 & 304.2 & 306.4 & 278.3 & 272.6 \\
\hline \multicolumn{7}{|l|}{ включая: } \\
\hline жилое здание & 223.0 & 239.1 & 283.0 & 286.1 & 259.5 & 253.8 \\
\hline нежилые здания & 18.4 & 19.0 & 21.2 & 20.3 & 18.8 & 18.8 \\
\hline $\begin{array}{l}\text { Общий объем строительства - } \\
\text { общее количество, млн. м3 }\end{array}$ & 485.6 & 526.7 & 617.8 & 622.8 & 608.5 & 599.4 \\
\hline \multicolumn{7}{|l|}{ включая: } \\
\hline жилое здание & 316.9 & 343.5 & 404.4 & 415.7 & 400.4 & 401.3 \\
\hline нежилые здания & 168.7 & 183.2 & 213.4 & 207.1 & 208.1 & 198.1 \\
\hline $\begin{array}{l}\text { Общая площадь застройки - } \\
\text { всего, млн. м2 }\end{array}$ & 110.4 & 117.8 & 138.6 & 139.4 & 135.8 & 137.3 \\
\hline \multicolumn{7}{|l|}{ включая: } \\
\hline жилое здание & 82.0 & 87.1 & 104.4 & 106.2 & 103.4 & 104.6 \\
\hline нежилые здания & 28.4 & 30.7 & 34.2 & 33.2 & 32.4 & 32.7 \\
\hline
\end{tabular}


Таблица 3. Объем работ по направлению экономической деятельности «гражданское строительство» в Российской Федерации (2010-2018 гг.)

\begin{tabular}{|c|c|c|}
\hline Период & $\begin{array}{c}\text { Млрд руб. в фактических } \\
\text { ценах на тот момент }\end{array}$ & $\begin{array}{c}\text { В процентах (в сопоставимых } \\
\text { ценах) к предыдущему году }\end{array}$ \\
\hline 2010 & $3,998.3$ & 86.8 \\
\hline 2011 & $4,454.1$ & 105.0 \\
\hline 2012 & $5,140.3$ & 105.1 \\
\hline 2013 & $5,714.1$ & 102.5 \\
\hline 2014 & $6,019.5$ & 100.1 \\
\hline 2015 & $6,125.2$ & 97.7 \\
\hline 2016 & $7,010.4$ & 96.1 \\
\hline 2017 & $7,204.2$ & 97.8 \\
\hline 2018 & $7,545.9$ & 98.6 \\
\hline
\end{tabular}

экономике отражены в следующих данных, приведенных в таблице 4 (Росстат, 2019б).

Анализ численности занятого населения свидетельствует о положительной динамике изменения структуры человеческого капитала в Российской Федерации, что отражает тенденцию увеличения доли высококвалифицированных работников. По сравнению с 2013 годом численность населения с высшим образованием увеличилась на 13\%, а численность занятых всего на $0,83 \%$.

Анализ динамики структуры безработного населения показывает (таблица 5) (Росстат, 2019б), что люди с высшим образованием представляют меньшую группу (в два раза) среди безработных со средним профессиональным образованием, что свидетельствует о большом спросе на человеческий капитал в российской национальной экономике [5].

Что касается сферы НИОКР, то можно отметить, что в 2013-2018 году практически не произошло изменений в численности занятых (таблица 6), что нельзя расценивать как положительную тенденцию в сфере инновационного развития и создания высокотехнологичных рабочих мест (Росстат, 2019д). Ниже мы более подробно проанализируем качественный состав группы «исследователи» (таблица 7).

В таблице 7 приведены данные по группе исследователей (по данным официального сайта Федеральной службы государственной статистики). Можно отметить, что исследователи с высшим техническим образованием составляют большинство (что соответствует международной практике). Однако только треть этой группы имеет научную степень; в среднем это три кандидата наук против одного доктора наук. Соотношение между теми, кто занимается техническими науками, и теми, кто занимается гуманитарными науками, составляет 18:1. Это соотношение, вероятно, свидетельствует о строго «прикладной» направленности исследовательской деятельности. Исходя из этих данных, можно прогнозировать, что Россия не обладает необходимым потенциалом для стимулирования «всплеска» инновационного развития. Гуманитарные дисциплины направлены на развитие потенциала общества в области социальных инноваций, а также занимаются формированием определенного менталитета, чувствительного к инновациям [4, с. 248]. Низкая доля исследований в области гуманитарных наук свидетельствует

Таблица 4. Занятое население в разбивке по уровню образования

\begin{tabular}{|l|c|c|c|c|c|c|c|}
\hline \multicolumn{1}{|c|}{ Год } & 2013 & 2014 & 2015 & 2016 & 2017 & 2018 \\
\hline $\begin{array}{l}\text { занятые - общая численность } \\
\text { (тыс. чел. люди) }\end{array}$ & 71,545 & 71,391 & 71,539 & 72,324 & 72,393 & 72,142 \\
\hline \multicolumn{2}{l|}{ среди них и с образованием: } & 21,740 & 22,616 & 23,045 & 23,847 & 24,216 & 24,698 \\
\hline \multicolumn{2}{l|}{ высшее образование } & 32,703 & 31,634 & 32,104 & 32,521 & 32,624 & 32,359 \\
\hline $\begin{array}{l}\text { среднее профессиональное } \\
\text { образование }\end{array}$ & 14,236 & 14,446 & 13,745 & 13,322 & 13,107 & 12,534 \\
\hline среднее общее образование & 2,671 & 2,511 & 2,484 & 2,485 & 2,315 & 2,397 \\
\hline основное общее образование & 196 & 181 & 160 & 147 & 129 & 154 \\
\hline нет базового общего образования & & & & &
\end{tabular}


Таблица 5. Численность безработных в разбивке по уровню образования

\begin{tabular}{|c|c|c|c|c|c|c|}
\hline Год & 2013 & 2014 & 2015 & 2016 & 2017 & 2018 \\
\hline безработных - всего (тыс. чел. люди) & 4,131 & 4,137 & 3,889 & 4,264 & 4,243 & 3,967 \\
\hline \multicolumn{7}{|l|}{ среди них и с образованием: } \\
\hline высшее образование & 676 & 721 & 709 & 839 & 868 & 819 \\
\hline $\begin{array}{l}\text { среднее профессиональное } \\
\text { образование }\end{array}$ & 1,638 & 1,608 & 1,551 & 1,744 & 1,716 & 1,590 \\
\hline среднее общее образование & 1,355 & 1,376 & 1,223 & 1,257 & 1,266 & 1,155 \\
\hline основное общее образование & 416 & 395 & 372 & 385 & 368 & 361 \\
\hline нет базового общего образования & 46 & 38 & 35 & 40 & 27 & 41 \\
\hline
\end{tabular}

Таблица 6. Персонал, занятый в НИОКР

\begin{tabular}{|c|c|c|c|c|c|c|}
\hline Год & 2012 & 2013 & 2014 & 2015 & 2016 & 2017 \\
\hline \multicolumn{7}{|l|}{ Российская Федерация } \\
\hline Персонал-общее количество (чел.) & 736,540 & 735,273 & 726,318 & 727,029 & 732,274 & 738,857 \\
\hline \multicolumn{7}{|l|}{ включая: } \\
\hline исследователи & 368,915 & 374,746 & 372,620 & 369,015 & 373,905 & 379,411 \\
\hline техперсонал & 59,276 & 61,562 & 58,905 & 61,401 & 63,168 & 62,805 \\
\hline вспомогательный персонал & 183,713 & 178,494 & 175,790 & 175,365 & 173,554 & 174,056 \\
\hline другие сотрудники & 124,636 & 120,471 & 119,003 & 121,248 & 121,647 & 122,585 \\
\hline \multicolumn{7}{|l|}{ Санкт-Петербург } \\
\hline Персонал-общее количество (чел.) & 79,813 & 81,000 & 80,660 & 78,773 & 78,727 & 79,076 \\
\hline \multicolumn{7}{|l|}{ включая: } \\
\hline исследователи & 43,555 & 44,676 & 45,503 & 43,932 & 43,317 & 42,956 \\
\hline техперсонал & 5,549 & 5,001 & 4,528 & 5,063 & 4,852 & 5,104 \\
\hline вспомогательный персонал & 17,376 & 17,416 & 17,993 & 17,372 & 17,773 & 18,149 \\
\hline другие сотрудники & 13,333 & 13,907 & 12,636 & 12,406 & 12,785 & 12,867 \\
\hline
\end{tabular}

Таблица 7. Численность исследователей по отраслям науки

\begin{tabular}{|c|c|c|c|c|c|c|}
\hline Год & 2012 & 2013 & 2014 & 2015 & 2016 & 2017 \\
\hline \multicolumn{7}{|l|}{ Российская Федерация } \\
\hline $\begin{array}{l}\text { Научные сотрудники - } \\
\text { общее количество (чел.) }\end{array}$ & 374,746 & 372,620 & 369,015 & 373,905 & 379,411 & 370,379 \\
\hline \multicolumn{7}{|l|}{ который: } \\
\hline занимается техническими науками & 226,492 & 225,118 & 225,082 & 226,682 & 231,809 & 225,038 \\
\hline занимается гуманитарными науками & 11,828 & 12,631 & 11,740 & 12,565 & 12,891 & 12,328 \\
\hline $\begin{array}{l}\text { Научные сотрудники с ученой степенью - } \\
\text { общее количество }\end{array}$ & 109,493 & 109,330 & 108,248 & 109,598 & 111,533 & 108,388 \\
\hline \multicolumn{7}{|l|}{ среди них со следующей ученой степенью: } \\
\hline доктор философии & 78,325 & 81,818 & 81,546 & 80,763 & 81,629 & 83,487 \\
\hline доктор & 26,789 & 27,675 & 27,784 & 27,485 & 27,969 & 28,046 \\
\hline
\end{tabular}


о том, что состояние формирования инновационной среды в России далеко неблагоприятное. В целом эту ситуацию можно охарактеризовать как негативную (в контексте инновационного развития). Более того, «стабильность» ситуации с точки зрения структуры можно рассматривать как негативный аспект. В 2013-2018 годах не произошло качественных изменений ни в численности персонала, ни в соотношении уровня образования к направленности профессиональной деятельности тех, кто занимается научными исследованиями.

Анализ динамики организаций, занимающихся НИОКР (таблица 8), позволяет сформировать мнение о том, что положительная динамика наблюдается только в высших учебных заведениях (почти двукратный рост по сравнению с 2011 годом по данным официального сайта Федеральной службы государственной статистики). Также из данных таблицы 7 следует, что количество специализированных организаций (НИОКР, инжиниринг и проектирование) ежегодно сокращается, а количество организаций, имеющих НИОКР, инжиниринговые и проектные подразделения, растет (в 2017 году количество таких организаций выросло почти на $52 \%$ по сравнению с 2011 годом) [3, с. 259].

С одной стороны, эту тенденцию может можно считать позитивной, потому что интеграция науки и образования очевидна.
С другой стороны, учитывая, что динамика происходит на фоне «стабильности» структуры высшего образования по соотношению занятых в научно-исследовательских проектах и имеющих разные научные степени (см. таблицу 7), можно предположить, что образование утрачивает функцию социального института, регулирующего воспроизводство человеческого капитала в гражданском строительстве.

Кроме того, указанная тенденция может также свидетельствовать о прикладном характере исследований, что приведет к их ухудшению.

По данным за 2018 год, среднемесячная заработная плата работника, занятого в гражданском строительстве, составила 33678 рублей (таблица 9), что на $42 \%$ больше заработной платы 2012 года (Росстат, 2019С) [6]. Однако в целом заработная плата в гражданском строительстве снизилась всего на 14\% в пересчете на средний уровень по российской экономике. Исходя из этих данных, можно предположить, что привлекательность данного вида экономической деятельности на рынке труда (для квалифицированных специалистов) будет снижаться. Среднегодовая численность занятых в гражданском строительстве в 2018 году (таблица 10) составила более 5 млн. человек и увеличилась на $4 \%$ по сравнению с 2011 годом (Росстат, 2019б) [5].

В последние годы эффективность труда в России в целом имеет тенденцию к снижению

Таблица 8. Количество организаций, занимающихся НИОКР, по видам организаций в Российской Федерации

\begin{tabular}{|c|c|c|c|c|c|c|}
\hline Год & 2012 & 2013 & 2014 & 2015 & 2016 & 2017 \\
\hline \multicolumn{7}{|l|}{ Российская Федерация } \\
\hline Организации - общее количество (шт.) & 3,682 & 3,566 & 3,605 & 3,604 & 4,175 & 4,032 \\
\hline \multicolumn{7}{|l|}{ включая: } \\
\hline Научно-исследовательские организации & 1,782 & 1,744 & 1,719 & 1,689 & 1,708 & 1,673 \\
\hline инженерная организация & 364 & 338 & 331 & 317 & 322 & 304 \\
\hline проектно-изыскательские организации & 38 & 33 & 33 & 32 & 29 & 26 \\
\hline пилотная установка & 49 & 60 & 53 & 53 & 61 & 62 \\
\hline учреждения высшего образования & 581 & 560 & 671 & 702 & 1,040 & 979 \\
\hline $\begin{array}{l}\text { промышленные организации с научно- } \\
\text { исследовательскими, инженерными и } \\
\text { проектными отделами }\end{array}$ & 280 & 274 & 266 & 275 & 371 & 363 \\
\hline
\end{tabular}

Таблица 9. Среднемесячная номинальная заработная плата работников

\begin{tabular}{|l|c|c|c|c|c|c|c|}
\hline \multicolumn{1}{|c|}{ Год } & 2012 & 2013 & 2014 & 2015 & 2016 & 2017 & 2018 \\
\hline Итого в экономике (руб.) & 23,369 & 26,629 & 29,792 & 32,495 & 34,030 & 36,709 & 39,144 \\
\hline гражданское строительство & 23,682 & 25,951 & 27,701 & 29,354 & 29,960 & 32,322 & 33,678 \\
\hline
\end{tabular}


на фоне и без того низких значений эффективности (таблица 11) (по данным официального сайта Федеральной службы государственной статистики).

Также следует учитывать долю трудовых мигрантов в гражданском строительстве, которые компенсируют значительную часть дефицита трудовых ресурсов в отрасли.

На основе анализа состояния сектора гражданского строительства можно сделать следующие выводы:

- низкая квалификация работников, занятых в гражданском строительстве, и, как следствие, низкая эффективность труда, что во многом обусловлено устаревшими технологиями управления и производства (Фальтинский, Токунова, 2019);

- низкий уровень используемых инноваций, что не обеспечивает экономического роста строительного сектора;;

- отсутствие комплексного подхода к управлению портфелем ресурсов организации, который учитывал бы факторы быстрого развития.
Таким образом, интенсификация строительного производства требует инициирования и осуществления инновационных процессов, структурной перестройки для создания и развития наиболее инновационной деятельности как в масштабе организации, отрасли, так и в масштабе государства в целом. Комплексные программы планирования и развития инновационной деятельности, которые могут обеспечить координацию выполняемых работ, должны служить основой для проведения мероприятий по реорганизации сектора гражданского строительства.

В ходе данного исследования был проведен анализ строительного сектора и выявлен крайне низкий уровень инновационной активности в строительных организациях (в том числе из-за консервативного характера гражданского строительства как вида экономической деятельности). Однако на современном этапе развития общества именно инновации являются движущей силой экономического роста, как на уровне организации, так и экономики в целом.

Таблица 10. Среднегодовая численность занятых в гражданском строительстве

\begin{tabular}{|l|c|c|c|c|c|c|c|}
\hline \multicolumn{1}{|c|}{ Год } & 2012 & 2013 & 2014 & 2015 & 2016 & 2017 & 2018 \\
\hline $\begin{array}{l}\text { занятые - общая численность } \\
\text { (тыс. чел. люди) }\end{array}$ & 70,857 & 71,545 & 71,391 & 71,539 & 72,324 & 72,393 & 72,142 \\
\hline гражданское строительство & 5,106 & 5,320 & 5,392 & 5,419 & 5,475 & 5,201 & 5,258 \\
\hline
\end{tabular}

Таблица 11. Индекс эффективности труда в целом по России и в гражданском секторе Российской Федерации (в процентах к предыдущему году)

\begin{tabular}{|c|c|c|}
\hline Год & В экономике в целом & $\begin{array}{c}\text { В секторе гражданского } \\
\text { строительства }\end{array}$ \\
\hline 2011 & 103.2 & 99.6 \\
\hline 2012 & 103.8 & 105.2 \\
\hline 2013 & 103.2 & 101.6 \\
\hline 2014 & 101.8 & 99.8 \\
\hline 2015 & 100.7 & 100.8 \\
\hline 2016 & 98.9 & 102.3 \\
\hline 2017 & 100.2 & 97.6 \\
\hline
\end{tabular}




\section{Библиографический список}

1. Карякина И. Е., ПотапкинаЕ. К. Анализ современного состояния строительной отрасли РФ, проблемы и перспективы ее развития // Экономика и бизнес: теория и практика. 2019. № 5-2. URL: https://cyberleninka. ru/article/n/analiz-sovremennogo-sostoyaniya-stroitelnoy-otrasli-rf-problemy-i-perspektivy-ee-razvitiya (дата обращения: 21.09.2020).

2. Оборина А.В. Анализ состояния гражданского строительства в России // Научный журнал. 2016. № 3 (4). URL: https://cyberleninka.ru/article/n/analiz-sostoyaniya-grazhdanskogo-stroitelstva-v-rossii (дата обращения: 21.09.2020).

3. Пахомов Е. В., Овчинникова М. С. Текущее состояние строительной отрасли РФ // Молодой ученый.- 2019.№ 2.- С. 255-260.

4. Чекурдаев В.С. Жилищный фонд России: проблемы и перспективы развития // Международный журнал гуманитарных и естественных наук. - 2018. - № 4. - С. 247-251.

5. Федеральная служба государственной статистики (Росстат) (2019b). Рабочая сила, занятость и безработица в России (по результатам выборочных исследований рабочей силы). 2019. Росстат, Москва.

6. Федеральная служба государственной статистики (Росстат) (2019с). Россия в цифрах. 2019. Росстат, Москва.

7. Федеральная служба государственной статистики (Росстат) (2019d). Российские регионы. Основные характеристики субъектов РФ. 2019. Росстат, Москва. 